\title{
Quo Vadis Peran IMF bagi Perekonomian Indonesia
}

\author{
Suharto
}

International Monetary Fund (IMF) that built on December 31, 1945 until now has developed its member. The aim of IMF as written article 1 of articles agreement of international monetary fund. In long term development perspective, the changing of paradigm that guaranteed the justice. Indonesia has a rich natural resources but indonesian can not explore their natural resources. If Indonesian can explore their natural resources, Indonesia will become a welfare state without IMF. According to author of this writing that the principle of justice must become a main basic either in constructing or decision of economy strategy in Indonesia in the future.

$\mathrm{D}$ ana Moneter internasional (International Monetary Fund/IMF) didirikan pada 31 Desember 1945 hingga kini telah mengalami perluasan keanggotaan (gambar 1). Tujuan didirikannya IMF adalah (artikel 1 dari articles of agreement of international monetary fund):

1. Memajukan kerjasama moneter internasional melalui lembaga permanen yang menghasilkan kerangka untuk konsultasi dan kolaborasi terhadap persoalan-persoalan moneter internasional,

2. Memfasilitasi ekspansi dan pertumbuhan seimbang dalam perdagangan internasional, dan memberi kontribusi dalam memajukan dan memelihara tingkat kesempatan kerja, pendapatan riil yang tinggi serta mengembangkan sumberdaya produktif bagi anggota sebagai sasaran utama dalam kebijakan publik.

3. Memajukan stabilitas nilai tukar, memelihara keteraturan dalam alat tukar antar anggota, dan mencegah persaingan dalam depresiasi nilai tukar.
4. Membantu terciptanya sistem pembayaran multilateral yang mapan dan mengurangi restriksi perdagangan luar negeri untuk pertumbuhan perdagangan dunia.

5. Memberi keyakinan pada anggota - dalam penyediaan sumber-sumber dana yang aman, sehingga dapat melakukan koreksi penyesuaian yang salah dalam neraca pembayaran mereka tanpa merusak kemakmuran nasional ataupun internasional.

6. Membantu mengatasi ketidakseimbangan neraca pembayaran internasional anggotanya dalam durasi yang pendek.

Gambar 1 Perkembangan Keanggotaan, 1945 -2003 (jumlah negara)

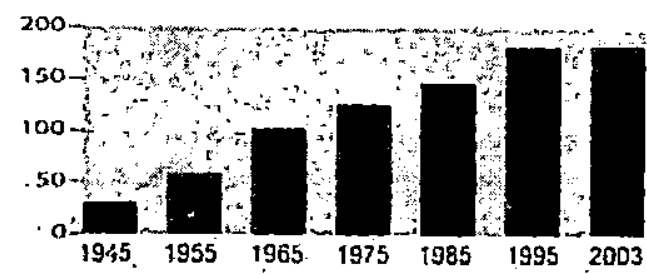

Sumber: IMF, 2003: 
Tabel 1 Perbandingan Indikator Ekonomi Tahun 1975 dan 2000

\begin{tabular}{|l|c|c|c|c|c|c|}
\hline \multirow{2}{*}{ Negara } & \multicolumn{2}{|c|}{ GDP perkapita (PPP/US } & \multicolumn{2}{c|}{ Harapan Hidup (tahun) } & \multicolumn{2}{c|}{$\begin{array}{c}\text { Buta Huruf } \\
\text { (persen) }\end{array}$} \\
\cline { 2 - 7 } & $\mathbf{1 9 7 5}$ & $\mathbf{2 0 0 0 .}$ & $\mathbf{1 9 7 5}$ & .2000 & 1975 & 2000 \\
\hline China & 273 & 3976 & 64.5 & 70.3 & 41.8 & 15.9 \\
Kenya & 400 & 1022 & 52.5 & 47.0 & 51.7 & 17.6 \\
Nigeria & 405 & 896 & 44.4 & 46.8 & 74.1 & 36.1 \\
Pakistan & 415 & 1928 & 52.3 & 63.0 & 75.7 & 56.8 \\
India & 461 & 2358 & 51.8 & 62.8 & 63.1 & 42.8 \\
Indonesia & 467 & 3043 & 51.3 & 66.0 & 37.1 & 13.1 \\
Sri Langka & 643 & 3530 & 66.2 & 73.1 & 17.0 & 8.4 \\
Mesir & 656 & 3635 & 53.3 & 67.5 & 64.7 & 44.7 \\
Ghana & 793 & 1964 & 51.2 & 56.9 & 63.6 & 28.5 \\
Thailand & 805 & 6402 & 60.6 & 68.8 & 15.5 & 4.5 \\
Pantai Gading & 901 & 1630 & 47.0 & 45.8 & 81.3 & 53.2 \\
Malaysia & 1274 & 9068 & 64.4 & 72.5 & 34.9 & 12.5 \\
Pilipina & 1502 & 3971 & 59.3 & 69.3 & 13.6 & 4.7 \\
Korea selatan & 1693 & 17380 & 63.9 & 73.2 & 9.8 & 2.2 \\
Brazil & 2304 & 7625 & 60.8 & 68.1 & 28.2 & 14.8 \\
Mexico & 2600 & 9023 & 64.2 & 73.0 & 21.3 & .8 .6 \\
\hline
\end{tabular}

Sumber: World Development Indicators (World Bank)

Jika IMF membantu anggotanya dalam mengatasi krisis ekonomi terutama yang terkait dengan neraca pembayarannya (balance of Payment/BOP) hal itu memang sudah seharusnya. Dua hal yang berkait dengan BOP adalah terkait dengan perdagangan dan keuangan, yang memang selalu menjadi persoalan yang dihadapi terutama oleh negara sedang berkembang. Dalam dataran riil peran IMF yang sering disebut dengan kebijakan penyesuaian struktural (structural adjusment policy/SAP) tidak dapat dikatakan benar-benar berhasil. $\mathrm{Hal}$ ini terlihat banyak pasien IMF yàng kambuh kembali setelah mengikuti SAP. Ambil contoh misalnya Argentina atau Amerika Latin secara keseluruhan yang menjadi pasien pada tahun 1970-an kembali mengalami krisis yang jauh lebih berat. Demikian juga Afrika, Turki, $:$ Rusia dan banyak negara lain yang tak kunjung sembuh dari sakitnya.
Namun demikian IMF tetap menyatakan bahwa mereka telah berhasil melakukan tugàsnya. Perekonomian dunia dikatakan terus menunjukkan arah yang semakin baik sebagaimana terlihat pada tabel 1 , ini adalah buktinya.

Mengacu pada tujuan-tujuan IMF seperti di atas, ketika Indonesia menghadapi krisis ekonomi berat semenjak pertengahan 1997, IMF hadir sebagai dewa penolong. Hal sama juga terjadi dengan Thailand, Korea Selatan dan beberapa negara lain di Asia Timur dan Asia Tenggara pada tahun 19971998. Hasil kerja IMF di beberapa negara ini dapat dikatakan berhasil jika dilihat dari beberapaindikator makro. Inflasi, nilai tukar, pinjaman luar negeri, pertumbuhan yang pósitip telah hádir kembali setelah masa kritis berakhir. Korea Selatan dan Thailand telah lebih dahúlu melakukan pengakhiran program pemulihan dengan IMF pada tahun . 2000. Barangkali yang perlu menjadi 
perhatian adalah kemungkinan kambuhnya krisis yang sama di masa datang, sebab kambuhannya justru akan lebih berat.

Indonesia memutuskan akan mengakhiri program pemulihan dengan IMF akhir tahun 2003 ini, selanjutnya IMF akan berperan dalam hal monitoring (post program monitoring/PPM). Sekali laggi Indonesia merupakan kasus khusus mengingat lambatnya pemulihan ekonomi yang terjadi. Dari sisi makro ada beberapa hal yang menggembirakan misalnya inflasi yang cenderung rendah, nilai rupiah relatif stabil, pinjaman luar negeri yang berkurang. Disamping ada juga beberapa variabel yang mengindikasikan bahwa ekonomi Indonesia sama sekali belum pulih. Variabel-variabel tersebut antara lain (a) lambatnya pertumbuhan ekonomi,(b) lemahnya kepercayaan investor baik domestik/PMDN maupun asing/PMA, (c) tingginya tingkat pengangguran. Beberapa kondisi ini meninggalkan "bom waktu" yang setiap saat dapat meledak, terlebih jika dikaitkan dengan masalah keamanan (terorisme dan berbagai konflik horisontal) dan politik (pemilu 2004). Dalam hal ini secara ekstrem ada yang menyatakan sebenarnya peran IMF di Indonesia telah gagal. Jika pemerintah kemudian memutuskan pengakhiran kontrak dengan IMF sebenarnya harus dimanfaatkan sebaikbaiknya.

\section{Hubungan Indonesia-IMF Semenjak Krisis}

Program bantuan IMF kepada indonesia tertuang dalam apa yang disebut dengan letters of intent/LOIs, yang merupakan sekumpulan unsur utama dalam kebijakan pemerintah dalam perekonomian dan keuangan secara keseluruhan. LOIs dimasukkan dalam berbagai dokumen kebijakan domestik pemerintah seperti PROPENAS (program pembangunan nasional 5 tahunan), REPETA (rencana pembangunan tahunan) dan anggaran/ APBN. LOIs ini dapat dilakukan penyesuaian jika diperlukan sehingga Indonesia melakukan revisi berulangkali (selama 4 tahun). Perubahan ini didasarkan pada kondisi aktual dan prioritas struktural serta pembangunan. Tabel 2 menunjukkan kerangka kerja antara Indonesia dan IMF.

Seperti disinggung diatas peran IMF di Indonesia juga menggunakan apa yang disebut program penyesuaian struktural. Jadi jaminan pinjaman IMF harus diikuti oleh program-program yang digariskan oleh IMF. Dalam hal ini LOIs adalah gambaran tegas dari program-program tersebut. Tabel 3 menunjukkan beberapa garis besar program penyesuain struktural dalam LOls.

Program penyesuaian struktural sangat memukul kelompok miskin yang sebenarnya

Tabel 2 Kerangka Keja Indonesia dengan IMF .

\begin{tabular}{|l|c|c|c|c|c|c|}
\hline \multicolumn{1}{|c|}{ Bentuk Kerjasama } & $\begin{array}{c}\text { Tanggal } \\
\text { Persetujuan }\end{array}$ & \multirow{2}{*}{$\begin{array}{c}\text { Tanggal } \\
\text { Pengakhiran }\end{array}$} & \multicolumn{2}{|c|}{$\begin{array}{c}\text { Akses Dana } \\
\text { (Jutaan) }\end{array}$} & \multicolumn{2}{c|}{$\begin{array}{c}\text { Jumlah Pencairan } \\
\text { (jutaan) }\end{array}$} \\
\cline { 4 - 8 } & & & SDR & US \$ & SDR & US \$ \\
\hline Stand-by Arrangement/SBA & 5 Nop. 1997 & 25 Agt. 1998 & 8.3 & 11.4 & 3.7 & 4.9 \\
Extended Fund Facility/EFF & 25 Agt. 1998 & 4 Feb. 2000 & 5.4 & 7.2 & 3.8 & 5.2 \\
Extended Fund Facility & 4 Feb. 2000 & 31 Des. 2003 & 3.6 & 5.0 & 2.9 & 4.0 \\
\hline
\end{tabular}

Sumber: Finance Department IMF 
Tabel 3 Risalah Butir-butir Kebijakan Letter of Intent (Lol) IMF Terakhir

\begin{tabular}{|l|l|c|c|c|c|}
\hline No. & Kelompok & \multicolumn{3}{|c|}{ Kebijakan $^{\text {J Jumiah }}$} \\
\cline { 3 - 5 } & & Baru $^{1}$ & Lama $^{2}$ & Lanjutan $^{3}$ & \\
\hline 1 & Restrukturisasi Perbankan & 171 & 57 & 99 & 327 \\
2 & Restrukturisasi Hutang Swasta & 56 & 20 & 38 & 114 \\
3 & Desentralisasi & 22 & 2 & 17 & 41 \\
4 & Lingkungan & 12 & & 33 & 45 \\
5 & Fiskal & 76 & 36 & 57 & 169 \\
6 & Perdagangan Luar Negeri & 18 & 27 & 37 & 82 \\
7 & Deregulasi dan Investasi & 19 & 25 & 12 & 56 \\
8 & Reformasi Hukum & 31 & 11 & 17 & 59 \\
9 & Pinjaman dan Pemulihan Aset & 75 & 23 & 33 & 131 \\
10 & Kebijakan Moneter dan Bank Sentral & 44 & 48 & 13 & 105 \\
11 & Lain-lain & 11 & 6 & 9 & 26 \\
12 & Privatisasi dan BUMN & 39 & 20 & 61 & 120 \\
13 & Jaring Pengaman Sosial & 8 & 4 & 14 & 26 \\
\hline \multicolumn{2}{|r|}{ Total } & 582 & 279 & 440 & 1.301 \\
\hline
\end{tabular}

Sumber: Noorsy, Ichsanudin, Makalah Seminar Indonesia Pasca IMF, PPE UII 23 Juni 2003 Keterangan:

1) merupakan kebijakan baru yang belum pernah dicantumkan dalam LOI sebelumnya,

2) merupakan penulisan kembali kebijakan serupa dalam Lol sebelumnya,

3) merupakan kebijakan lanjutan dari kebijakan yang terdahulu.

paling resisten terhadap krisis ekonomi. Secara garis besar program penyesuaian struktural meliputi:

1. Pemotongan pengeluaran sosial (subsidi pemerintah) pada bidang pendidikan dan kesehatan, dan mengitrodusir pembayaran (fee) untuk mendapatkan pelayanan kesehatan dan sekolah yang sebelumnya relatif gratis (mengandung subsidi). Sebuah penelitian yang dilakukan Oxfam sebuah badan bantuan internasional di Afrika, sebuah badan bantuan internasional, menyebutkan dampak program semacam ini menyebabkan rata-rata 1 dari 5 anak meninggal sebelum usia 5 tahun, penyebaran beberapa penyakit, dan tingkat anak yang sekolah sangat rendah.
2. Pemotongan pegawai pemerintah, merubah hukum untuk membuat sektor swasta lebih mudah dalam merumahkan pegawai, menekan upah minimum; seperti terjadi di Haiti. Kebijakan seperti ini jelas akan membengkakkan pengangguran.

3. Mendorong negara-negara yang dibantu untuk membuat kebijakan yang kompatibel dengan perdagangan bebas. Hal ini justru memperburuk neraca pembayaran bagi negaranegara miskin.

Tentang peran IMF dikaitkan dengan proses globalisasi ini Știglitz mengkritisi halhal berikut:

1. Paket reformasi perdagangan selama tahun 1990-an tidak tepat dilihat dari urutan langkahnya. Menurutnya 
liberalisasi akan berhasil jika dilakukan dengan kecepatan dan urutan yang tepat." Negara sedang berkembang secara umum belum siap jika tiba-tiba harus melakukan liberalisasi perdagangan. Liberalisasi harus berjalan secara gradual dengan bantuan luar negeri yang subtansial, harus meminimumkan dampak pengangguran sebagai konsekuensi reformasi, untuk negara dengan inflasi tinggi persoalan ketidakseimbangan fiskal harus menjadi urutan pertama, reformasi finansial perlu dilakukan untuk menciptakan pengaturan dan pengawasan yang moderen, dan neraca modal harus merupakan langkah terakhir dari proses liberalisasi.

2. Dorongan (pemaksaan) liberalisasi neraca modal adalah kesalahan besar, karena hal ini dapat mendorong alokasi ke sektor konsumsi daripada investasi.

3. Resep yang diberikan IMF sebagai respon krisis justru memperburuk bencana daripada memperbaikinya, khususnya kebijakan di bidang kebijakan fiskal dan kenaikan suku bunga bank. Tentang kasus ini kesalahan besar dalam menangani krisis Asia adalah penutupan bank ditengah-tengah terjadinya kepanikan keuangan di Indonesia, penalangan utang swasta dan sebagian besar kepada kreditor asing, tidak membolehkan adanya kontrol kapital keluar, pemaksaan kebijakan fiskal ketat dan tingkat bunga tinggi.

Sisi gelap campur tangan IMF dalam perekonomian Indonesia dapat dilihat dari berbagai sisi. Dari sisi fiskal kebijakan IMF adalah menekankan pada mengurangi defisit fiskal, persoalan ini dicapai dengan mengurangi berbagai macam subsidi (BBM,
Listrik, air, pupuk, Telekomunikasi). Dari perspektif teoritis pengurangan subsidi pemerintah adalah sarana menuju ekonomi yang sehat, akan tetapi pencabutan subsidi pada saat masyarakat menghadapi kesulitan justru berakibat rusaknya kondisi sosial ekonomi secara keseluruhan. Pada sisi perdagangan luar negeri, IMF menganjurkan penurunan atau bahkan penghapusan bea masuk untuk berbagai produk termasuk produk strategis seperti beras dan gula. Kebijakan ini semakin menekan penerimaan pemerintah dari pajak ekspor dan impor serta jatuhnya harga barang-barang yang dihasilkan masyarakat miskin. Jadi tidak mengherankan apabila subsidi kepada masyarakat miskin ini secara berkelanjutan terus terjadi. Terakhir dengan semakin mahalnya pendidikan, merupakan indikasi lain dari nasihat IMF.

Terapi lain yang ditawarkan oleh IMF untuk pemulihan ekonomi adalah penalangan (bail out) utang swasta ini sama artinya dengan membuat subsidi untuk orang kaya. Akibatnya pinjaman dalam negeri pemerintah membengkak luar biasa sebagai akibat kebijakan tèrsebut, baik dalam bentuk obligasi rekapitalisasi yang besarnya mecapai Rp 412,58 trilyun (per April 2003), surat utang kepada Bank Indonesia (BI) sebesar Rp 228,29 trilyun (tabel 4).

Utang dalam negeri yang sangat besar tersebut berdampak pada perekonomian dalam beberapá aspek :

1. Beban yang dipikul oleh masyarakat àkan berkelanjutan apabila tidak ada tindakan untuk merestrukrisasi utang dalam nègeri pemerintah ini. Proses semacam itu tidak saja meriyulitkan pemerintah dalamaalokasi pengeluaran

1 J.E.Stiglitz, 2001, Globalization and its Discontent, New York and London:W.W. Norton Publisher, hlm. 73-78. 
Tabel 4 Posisi Utang Pemerintah dan Swasta

\begin{tabular}{|c|c|c|c|}
\hline No. & \multicolumn{2}{|c|}{ Jenis pinjaman } & Jumlah \\
\hline 1 & $\begin{array}{l}\text { Pinjaman Luar } \\
\text { Desember 2002) } \\
\text { a. Pemerinta } \\
\text { b. Swasta } \\
\text { Total }\end{array}$ & geri Pemerintah dan Swasta (per & $\begin{array}{l}\$ 74,2 \text { milyar } \\
\$ 56,7 \text { milyar } \\
\$ 130,9 \text { milyar }\end{array}$ \\
\hline 2 & $\begin{array}{r}\text { Pinjaman Dalam i } \\
\text { a. Obligasi } \\
\text { Terdiri dari: } \\
\text { (i) } \\
\text { (ii) } \\
\text { (iii) } \\
\text { b. Surat Uta } \\
\text { Terdiri dari: } \\
\text { (i) } \\
\text { (ii) } \\
\text { (iii) } \\
\text { (iv) } \\
\text { Total }\end{array}$ & $\begin{array}{l}\text { geri Pemerintah (per } 25 \text { April 2003) } \\
\text { kap } \\
\text { obligasi bunga tetap } \\
\text { obligasi bunga mengambang } \\
\text { obligasi lindung nilai } \\
\text { Kepada Bank Indonesia } \\
\text { BLBI yang dibayarkan tanggal } 29 \\
\text { januari 1999 } \\
\text { Penyediaan dana konvensi saldo } \\
\text { debet menjadi penyertaan modal } \\
\text { pada Bank Exim (PP 60/1998) } \\
\text { Program Penjaminan untuk bank } \\
\text { umum dan bank perkreditan rakyat } \\
\text { Kredit program dalam bentuk surat } \\
\text { utang No. SU-005/MK/1999 }\end{array}$ & $\begin{array}{l}\text { Rp. } 412,58 \text { trilyun } \\
\text { Rp. } 153,77 \text { trilyun } \\
\text { Rp. } 236,97 \text { trilyun } \\
\text { Rp. } 21,84 \text { trilyun } \\
\text { RP. } 228,29 \text { trilyun } \\
\text { Rp. } 144,54 \text { trilyun } \\
\text { Rp. } 20 \text { trilyun } \\
\text { Rp. } 53,78 \text { trilyun } \\
\text { Rp. } 9,97 \text { trilyun } \\
\text { Rp. } 640,87 \text { trilyun }\end{array}$ \\
\hline
\end{tabular}

Sumber: Sri-Edi Swasono, Makalah seminar Indonesia Pasca IMF, PPE FE UI, 23 Juni 2003

pada anggaran penerimaan dan belanja negara (APBN), tetapi seperti disinggung di atas menjadi tidak fair karena justru masyarakat yang menjadi korban krisis harus memberikan subsidi kepada kelompok kaya yang sebenarnya sebagai pencetus krisis. Sustainability dari beban masyarakat ini saat ini antara lain menjelma pada mahalnya pendidikan termasuk di lembaga pemerintah sekalipun, ini menjadi janggal karena dimaná pun pendidikan 'dan kesehatan adalah tanggung jawab pemerintah;
2. Menghambat terjadinya pemulihan sektor riil secara subtansial. Hal ini sangat terasa bagaimana bunga kredit sangat sulit turun (seperti upah nominal yang mengalami ketegaran saat bergerak turun) meskipun suku bunga Sertifikat Bank indonesia (SBI) sudah mengalami penurunan cukup siknifikan (menembus level $9,30 \%$ per $3 \mathrm{Juli}$ 2003). Alotnya proses penurunan suku bunga kredit jelas berhubungan erat dengan utang dalam negeri khususnya menyangkut obligasi rekap yang sangat besar tadi. Selama periode 
krisis bank-bank justru mereguk untung yang luar biasa dari bunga obligasi rekap ini, sehingga pada saat bunga obligasi turun maka keuntungan juga akan menurun, sudah pasti bank tidak akan mudah menurunkan suku bunga kredit justru akan menjadikannya sebagai pengalihan sumber pendapatan meskipun bersifat trasisional. Jadi dapat disimpulkan sektor riil terutama sektor usaha kecil dan menengah masih sulit mendapatkan dana murah dari perbankan;

3. Menumbuhsuburkan moral hazard, mengingat program program pemulihan IMF ini melibatkan teknis administratif yang luar biasa luas (melibatkan $\mathrm{Bl}$, Pemerintah, DPR, BPPN, IMF dan lembaga terkait baik di dalam maupun di luar negeri lainnya). Sebagai indikasi misalnya audit Badan Pemeriksa Keuangan (BPK) menyebutkan dari 144,54 trilyun rupiah BLBI ada sekitar 84,5 trilyun yang belum dapat dipertanggungjawabkan oleh $\mathrm{Bl}$, hal ini tentu dapat ditafsirkan macam-macam. Tentang BPPN, merujuk pada lembaga sejenis di Mexico, bahwa setelah program selesai maka orang-orang yang terlibat dalam lembaga tersebut masuk dalam daftar hitam orang-orang tercela dan ditolak diberbagai tempat dalam mencari kerja. Kita tak perlu berargumentasi lebih jauh bagaimana tentang BPPN kita, yang jelas perusahaan-perusahaan yang ikut dalam program penyehatan mendapatkan dana rekap dan bentuk-bentuk lainnya senilai ratusan trilyun tetapi ketika dilepas (divestasi saham pemerintah) nilai aset yang dijaminkan sangat jauh dari pantas, ambil contoh penjualan saham BCA, Indosat;
4. Ketergantungan kepada asing semakin besar, privatisasi yang membabi buta dan tidak didasarkan pada alasan yang benar (privatisasi seharusnya menjual aset-aset yang tidak produktif agar efisiensi dan laba perusahaan meningkat) menyebabkan jatuhnya berbagai perusahaan-perusahaan negara yang strategis telah jatuh dengan harga yang sangat murah ke tangan luar negeri. Hal inilah yang pada awal tulisan ini disebutkan bahwa IMF penuh pamrih dalam berbagai program pemulihannya. Secara logika, dalam berbisnis ketika seorang kreditor memberikan pinjaman kepada debitur dan kemudian macet atau gagal, maka semestinya resiko harus ditanggung kedua pihak, tetapi dengan program IMF justru membebankan sepenuhnya kepada seluruh masyarakat dimana debitur menjadi salah satu penduduknya.

\section{Penutup}

Harus diakui IMF punya andil dalam "kestabilan ekonomi" Indonesia saat ini. Kita dapat mengatakan karena kita menurut apa nasihatnya maka para spekulan untuk sementara tak melakukan aksinya di Indonesia. Pengakhiran kerjasama dengan melalui PPM membuka peluang yang sangat terbuka akan stabilitas tersebut. Tetapi di sisi lain peran IMF telah menciptakan bom waktu yang lain seperti pengangguran dan utang dalam negeri. Apabila tidak hati-hati maka krisis lebih besar akan selalu menghantui perjalanan perekonomian bahkan bangsa Indonesia secara keseluruhan.

Solusi-solusi dapat saja ditawarkan tetapi apakah dapat secara efektif dilakukan/ diimplementasikan itu persoalan lain lagi. 
Banyak ekonom kritis ketika di luar pagar kekusaan mengkritik dengan lantang tetapi begitu masuk dalam lingkaran kekuasaan akan segera duduk manis menikmati kursinya dan selalu berbicara tak ada masalah dengan pemerintah. Hal ini dapat ditafsirkan majemuk, pertama, harga sebuah idealisme murah, sudah duduk lupa berdiri. Kedua, kendala institusional dalam menerapkan kebijakan yang baik sungguh luar biasa besar. Kalau mengacu pada tafsir kedua, memang banyak sekali kendala tersebut, antara lain.

1. Birokrasi yang menggelembung, tampaknya tak banyak berubah semenjak era orde baru sampai sekarang. Kondisi semacam ini tidak saja menyebabkan ekonomi biaya tinggi bagi masyarakat yang paling miskin sekaligus juga menyuburkan mentalitas rent seeking para birokrat dari bawah sampai ke atas. Oleh karena itu langkah awal adalah menekankan bagaimana good governance dapat ditegakkan, agar kebijakan yang baik dapat diterapkan.

2. Para pengambil keputusan umumnya tak memiliki platform yang jelas, kecuali ikut mendapatkan keuntungan dari proses pengambilan keputusan. Profesionalisme dalam jabatan publik hampir nihil, ini terjadi dari eksekutif juga legislatif karena proses rekruitmen yang juga tidak profesional. Pada akhirnya langkah awal yang lain adalah membangun mekanisme untuk mewujudkan the right man on the right place agar profesinalisme dapat diwujudkan dalam segala tingkatan. Pemilu 2004 meskipun masyarakat secara umum skeptis dapat dijadikan momentum yang sangat mahal harganya. Bayangkan bagaimana kebijakan ideal dapat diterapkan jika mayoritas anggota DPR dan DPRD adalah broker.

3. Tiadanya kemauan para elit untuk melakukan perbaikan keadaan menuju ke arah terlaksananya kebijakan yang lebih baik. Semestinya langkah yang juga menjadi prioritas adalah membangun kode etik bersama seperti pembatasan gaji, pemilikan mobil, rumah dan lainnya bagi anggota DPR, DPRD, dan elit lainnya untuk membatasi distorsi berupa korupsi, pencucian uang dan sejenisnya.

4. Lemahnya penegakan hukum di segala bidang, hal ini sama sekali tidak mendidik bangsa ke arah kebaikan. Adalah lebih baik menjalankan hukum yang jelek dengan nurani yang benar, daripada tak pernah ada penegakan hukum.

Dalam Perspektif pembangunan jangka panjang maka perubahan paradigma pembangunan yang lebih adil. Bangsa indonesia di karuniai sumberdaya alam yang tak terhitung tetapi menyia-nyiakannya, padahal jika dimanfaatkan secara benar akan menjadi bangsa yang sejahtera (tanpa IMF). Praktek pembangunan selama ini lebih menguntungkan para pemilik modal dan merugikan masyarakat secara keseluruhan. Ke depan orientasi pembangunan yang mengedepankan keadilan harus mendapatkan tempat yang utama dalam penyusunan dan pengambilan keputusan ekonomi strategis. Pengalaman yang ada jika distribusi pendapatan tidak merata potensial terjadinya eksploitasi yang kuat terhadap yang miskin, disamping menimbulkan bom waktu kerusuhan sosial. 


\section{Daftar Pustaka}

Boorman, J. and Andrea R. Hume (2003), "Life with The IMF: Indonesian Choice for The Future", Makalah disampaikan pada kongres ISEI ke15, Batu, Malang, 13-15 Juli

Dokumen Indonesia Bangkit, Naskah Terbatas tak dipublikasikan.

Dunia Usaha Dukung PPM, Kompas, hal.14, Edisi 28 Juni 2003

International Monetary Fund, 2002, World Economic and Financial Development in FY 2002, Annual Report 2002 2003, About IMF, // uww.imf.org/external/about.htm

Lebih Jauh dengan David Ch. Nellor, Kompas, hal. 4 Edisi 22 Juni 2003.

Noorsy, I, 2003, "Indonesia Pasca IMF: Mencari Terobosan Sumber-sumber Pembiayaan Pasca IMF", Makalah Seminar di PPE FE UII, 23 Juni

Ramli, R. 2003, "Malpraktek dan Mitos IMF di Indonesia", Makalah disampaikan pada kongres ISEI ke-15, Batu, Malang, 13-15 Juli

Somerville Community News (2000), Huge April Protest Against IMF and World Bank in DC, WWW.the-ville.com/ scn/2000/11/huge_April.html.

Stiglitz, J.E. (2001), Globalization and Its Discontents, New York and London: W.W. Norton Publisher

Swasono, S, 2003, "Indonesia Pasca IMF: Solusi dan Prediksi", Makalah Seminar di PPE FE UII, 23 Juni

UNRISD 2000, Visible Hands: Taking Responsibility for Social Development. Geneva: UNRISD

World Bank 2002, World Development Indicators, London: oxford University Press.

Wood, A. 1997, "Opennes and wage Inequality in Developing Countries: the Latin America Challenge to East Asian Controversial Wisdom", The World bank Economic Review, Vol.11, No.1 